\title{
Mechanistic In Vitro Studies Indicate that the Clinical Drug-Drug Interaction between Telithromycin and Simvastatin Acid Is Driven by Time-Dependent Inhibition of CYP3A4 with Minimal Effect on OATP1B1
}

\author{
Robert Elsby, Victoria Hare, Hannah Neal, Samuel Outteridge, Catherine Pearson, Katie Plant, \\ Rachel Upcott Gill, Philip Butler, and Robert J. Riley
}

Department of ADME Sciences, Cyprotex Discovery Ltd. (an Evotec company), Macclesfield, Cheshire, United Kingdom (R.E., V.H., H.N., S.O., C.P., K.P., R.U.G., P.B.); and Drug Metabolism and Pharmacokinetics, Evotec, Abingdon, Oxfordshire, United Kingdom (R.J.R.)

Received August 3, 2018; accepted October 18, 2018

\section{ABSTRACT}

A previous attempt to accurately quantify the increased simvastatin acid exposure due to drug-drug interaction (DDI) with coadministered telithromycin, using a mechanistic static model, substantially underpredicted the magnitude of the area under the plasma concentration-time curve ratio (AUCR) based on reversible inhibition of CYP3A4 and organic anion transporting polypeptide 1B1 (OATP1B1). To reconcile this disconnect between predicted and clinically observed AUCR, telithromycin was evaluated as a timedependent inhibitor of CYP3A4 in vitro, as well as an inhibitor of OATP1B1. Telithromycin inhibited OATP1B1-mediated $\left[{ }^{3} \mathrm{H}\right]-$ estradiol $17 \beta$-D-glucuronide $(0.02 \mu \mathrm{M})$ transport with a mean $\mathrm{IC}_{50}$ of $12.0 \pm 1.45 \mu \mathrm{M}$ and was determined by $\mathrm{IC}_{50}$ shift and kinetic analyses to be a competitive reversible inhibitor of CYP3A4mediated midazolam1- hydroxylation with a mean absolute inhibition constant $\left(\mathrm{K}_{\mathrm{i}}\right)$ value of $3.65 \pm 0.531 \mu \mathrm{M}$. The 2.83 -fold shift in $\mathrm{IC}_{50}$
(10.4-3.68 $\mu \mathrm{M})$ after a 30-minute metabolic preincubation confirmed telithromycin as a time-dependent inhibitor of CYP3A4; the mean inhibitor concentration that causes half-maximal inactivation of enzyme $\left(K_{\mathfrak{l}}\right)$ and maximal rate of inactivation of enzyme ( $\left.\boldsymbol{K}_{\text {inact }}\right)$ values determined for inactivation were $1.05 \pm 0.226 \mu \mathrm{M}$ and $0.02772 \pm 0.00272 \mathrm{~min}_{-1}$, respectively. After the integration of an enzyme time-dependent inhibition component into the previous mechanistic static model using the in vitro inhibitory kinetic parameters determined above, the newly predicted simvastatin acid AUCR (10.8 or 5.4) resulting from perturbation of its critical disposition pathways matched the clinically observed AUCR (10.8 or 4.3) after coadministration, or staggered administration, with telithromycin, respectively. These results indicate the time-dependent inhibition of CYP3A4 by telithromycin as the primary driver underlying its clinical DDI with simvastatin acid.

\section{Introduction}

Simvastatin acid, administered as inactive lactone simvastatin at an oral dose of 5-80 mg/day, is a 3-hydroxy-3-methylglutarylcoenzyme-A reductase inhibitor (statin) that was developed to treat hypercholesterolemia (www.accessdata.fda.gov/drugsatfda_docs/label/ 2012/019766s085lbl.pdf). The critical disposition pathways of simvastatin acid, after its formation from the lactone in the intestinal wall, and their contributions to overall clearance [fraction metabolized $\left(f_{\mathrm{m}}\right)$ or fraction excreted $\left(f_{\mathrm{e}}\right)$ values] have been determined previously based on derivation from clinical human mass balance, pharmacogenetics, and drug-drug interaction (DDI) evidence (Elsby et al., 2012). These pathways include intestinal CYP3A4 $\left(f_{\mathrm{m}}=0.4\right)$ as the barrier to simvastatin acid absorption, and the hepatic uptake transporter organic anion transporting polypeptide $1 \mathrm{~B} 1\left(\mathrm{OATP} 1 \mathrm{~B} 1 ; f_{\mathrm{e}}=0.79\right)$ and hepatic

https://doi.org/10.1124/dmd.118.083832.
CYP3A4 $\left(f_{\mathrm{m}}=0.83\right)$ which are responsible for hepatic elimination of simvastatin acid (Elsby et al., 2012).

DDIs with simvastatin acid are of clinical concern as elevated systemic concentrations of statins, due to perturbation of critical disposition pathways, are associated with increased muscle exposure and risk of myopathy or even fatal rhabdomyolysis in extreme cases (Egan and Colman, 2011). Indeed, clinically significant DDIs [resulting in up to 10-fold increases in simvastatin acid exposure, defined as the area under the plasma concentration-time curve (AUC)] have been observed between simvastatin acid and CYP3A4 inhibitors such as telithromycin and clarithromycin (www.accessdata.fda.gov/drugsatfda_docs/label/2012/019766s085lbl.pdf, www.accessdata.fda.gov/drugsatfda_docs/label/2010/021144s014lbl.pdf). Furthermore, DDIs can also result from the inhibition of OATP1B1 either alone [e.g., with gemfibrozil; simvastatin acid AUC ratio $($ AUCR) $=2.85$ ] or in combination with the inhibition of CYP3A4 (e.g., with cyclosporine; simvastatin acid AUCR = 8.0) (Elsby et al., 2012).

ABBREVIATIONS: AICc, corrected Akaike information criterion; AUC, area under the plasma concentration-time curve; AUCR, area under the plasma concentration-time curve ratio; DDI, drug-drug interaction; DMSO, dimethylsulfoxide; $f_{\mathrm{e}}$, fraction excreted; $f_{\mathrm{m}}$, fraction metabolized; [l], inhibitor concentration; $\mathrm{k}_{\mathrm{deg}}$, apparent first-order degradation constant of enzyme; $\mathrm{K}_{\mathrm{i}}$, absolute inhibition constant; $\mathrm{K}_{\mathrm{l}}$, inhibitor concentration that causes half-maximal inactivation of enzyme; $k_{\text {inact }}$, maximal rate of inactivation of enzyme; $K_{m}$, Michaelis-Menten kinetic constant; $k_{o b s}$, inactivation rate constant; OATP, organic anion transporting polypeptide 1B1; P450, cytochrome P450; [S], probe substrate concentration. 
Understanding the potential for a new investigational drug to perpetrate DDIs with coadministered medications in the clinic is an important part of the drug discovery and development process. Such analysis involves initial in vitro evaluation of the drug as an inhibitor of individual enzymes/transporters to determine an absolute inhibition constant $\left(\mathrm{K}_{\mathrm{i}}\right)$, which is then put into context with anticipated concentration at the interaction site using basic static equations detailed in regulatory guidance (http://www.fda.gov/downloads/Drugs/GuidanceComplianceRegulatoryInformation/Guidances/UCM581965.pdf). However, the industry is moving toward adopting mechanistic static model approaches that allow the calculation of theoretical AUCR changes for victim drugs due to the inhibition of multiple critical disposition pathways to enable more effective, quantitative, predictions of increasingly complex DDIs (Williamson and Riley, 2017). Such predictions can be used during drug discovery or development to inform either decision-making or clinical protocol design for patient studies, respectively (Williamson and Riley, 2017).

One such published mechanistic static model described the prediction of AUCRs for 20 clinically observed DDIs with six statin drugs after inhibition of one or more drug (victim)-specific critical disposition pathways (Elsby et al., 2012). This model successfully predicted $90 \%$ of DDIs within 2-fold of the clinically observed AUCR (Williamson and Riley, 2017). Interestingly, one of the two DDIs that was not predicted in the model was the interaction between simvastatin acid and telithromycin, which underpredicted the observed DDI almost 3-fold (predicted AUCR $=4.0$ ), based upon composite inhibition of intestinal CYP3A4 (predicted 1.67-fold AUC increase), hepatic OATP1B1 (predicted 1.2fold AUC increase), and hepatic CYP3A4 (predicted 2.0-fold AUC increase). The authors hypothesized that this underprediction of AUCR could be due to telithromycin being a possible time-dependent inhibitor of CYP3A4 in vivo based on the findings of a sponsor-conducted clinical trial demonstrating a reduced (compared with coadministration) but clinically significant DDI between the drugs even when they are administered 12 hours apart. If this was indeed the case, then the Rowland-Matin equation used in the model would be expected to underestimate AUCR as it only considers reversible cytochrome P450 (P450) inhibition (Elsby et al., 2012). However, although a recent report (Vieira et al., 2012) used an in silico model to estimate time-dependent inhibitory parameters for telithromycin toward verifying such a mechanism, as far as these authors can observe from searching the literature, to date no study appears to have been reported that has confirmed whether telithromycin is a time-dependent inhibitor of CYP3A4 in vitro.

Therefore, the aims of this study were to investigate telithromycin as both a reversible and time-dependent inhibitor of CYP3A4 in pooled human liver microsomes and to use the in vitro determined enzyme inhibitory kinetic parameters, alongside that determined against OATP1B1. Using these data in a modified version of the mechanistic static statin model described by Elsby et al. (2012), now integrating a time-dependent (inactivation) component for enzyme (CYP3A4), an attempt was made to reconcile the disconnect between the predicted and observed AUCRs for the clinical DDI with simvastatin acid.

\section{Materials and Methods}

\section{Materials}

Estradiol 17 $\beta$-D-glucuronide, ketoconazole, metoprolol, mifepristone, rifamycin SV, midazolam, NADPH, sodium butyrate, nonessential amino acids, and HEPES were purchased from Sigma-Aldrich (Poole, Dorset, UK). Telithromycin was purchased from Toronto Research Chemicals (Toronto, ON, Canada). Midazolam was purchased from Tocris Bioscience (Oxfordshire, UK). $\left[{ }^{3} \mathrm{H}\right]-$ Estradiol $17 \beta$-D-glucuronide, Optiphase Supermix liquid scintillation cocktail, and 24-well liquid scintillation counting visiplates were purchased from PerkinElmer Life and Analytical Sciences (Buckinghamshire, UK). Hanks' balanced salt solution (containing $\mathrm{CaCl}_{2}$ and $\mathrm{MgCl}_{2}$; Thermo Fisher Scientific, Loughborough, UK), Dulbecco's modified Eagle's medium (high glucose with GlutaMax and pyruvate; Thermo Fisher Scientific), fetal bovine serum (heat inactivated; Thermo Fisher Scientific), and mammalian protein extraction reagent were purchased from Thermo Fisher Scientific. All other chemicals, solvents, and reagents were purchased from Thermo Fisher Scientific.

Biocoat poly-D-lysine 24-well multiwell plates, human OATP1B1 (SLCO1B1)-expressing TransportoCells, vector control cells, and pooled human liver microsomes were supplied by Corning BV Life Sciences (Amsterdam, The Netherlands). Ninety-six-well deep-well Abgene polypropylene plates, 96-well v-bottom polypropylene plates, 96-well deep well 1-ml polypropylene plates, or 96-well shallow round-bottomed polypropylene plates were supplied by Thermo Fisher Scientific.

\section{Assessment of Telithromycin as an Inhibitor of OATP1B1}

OATP1B1 and vector control cell lines were seeded in cell culture medium (consisting of Dulbecco's modified Eagle's medium supplemented with 10\% w/v fetal bovine serum and $1 \% \mathrm{v} / \mathrm{v}$ nonessential amino acids) at $3-4 \times 10^{5}$ cells/well in 24-well poly-D-lysine-coated plates to achieve a preassay confluence of typically $80 \%-95 \%$. The media were changed $3-4$ hours postseeding, and the cells were cultured in media containing $2 \mathrm{mM}$ sodium butyrate at $37^{\circ} \mathrm{C}, 8 \% \mathrm{CO}_{2}$ for 24 hours. Prior to the assay, cells were washed twice with prewarmed uptake buffer (Hanks' balanced salt solution containing $10 \mathrm{mM}$ HEPES, pH 7.4) then were left to preincubate with telithromycin $(0.3,1,3,10,30$, or $100 \mu \mathrm{M})$ in warm uptake buffer for 15 minutes. After the preincubation, uptake buffer was removed and the appropriate incubation solutions were added to the wells.

Uptake of the probe substrate $\left[{ }^{3} \mathrm{H}\right]$-estradiol $17 \beta$-D-glucuronide $(0.02 \mu \mathrm{M})$ was determined (in triplicate wells per condition, on three separate occasions) over a 2-minute incubation time at $37^{\circ} \mathrm{C}$ in OATP1B1-expressing cells and vector control cells, in the absence and presence of telithromycin $(0.3,1,3,10,30$, or $100 \mu \mathrm{M})$ or the positive control inhibitor rifamycin SV $(100 \mu \mathrm{M})$, at a final dimethylsulfoxide (DMSO) concentration of $1 \%(\mathrm{v} / \mathrm{v})$. At the end of the incubation, active transport processes were terminated by removing (via aspiration) the incubation solutions, immediately washing the cells twice with ice-cold uptake buffer and then placing plates on ice. After the wash steps, mammalian protein extraction reagent $(400 \mu \mathrm{l})$ was added to each well and cells were lysed for at least 5 minutes at $250 \mathrm{rpm}$ on an orbital shaker. An aliquot $(300 \mu \mathrm{l})$ of cell lysate was added to a white-walled, clear bottomed, 24-well visiplate, liquid scintillation cocktail ( $2 \mathrm{ml})$ was added, and samples were counted on a MicroBeta ${ }^{2}$ Scintillation Counter (PerkinElmer) to determine the total radioactivity (in disintegrations per minute) taken up in cells. Separately, the protein content of cell lysates $(25 \mu \mathrm{l})$ was determined using a BCA protein assay kit according to the manufacturer instructions.

For data analysis, the determined total uptake of probe substrate $\left[{ }^{3} \mathrm{H}\right]$-estradiol $17 \beta$-D-glucuronide into cells (in picomoles) was normalized to the protein (in milligrams) content of each well to calculate the uptake activity (picomoles per milligram). The uptake activity of probe substrate into transporter-expressing cells was corrected for that determined in vector control cells to calculate the transporter-mediated (corrected) uptake. Corrected uptake activity (in picomoles per milligram) was converted to a percentage of (vehicle) control activity, which was subsequently plotted against nominal inhibitor concentration and fitted using SigmaPlot 12.5 (Systat Software Inc., Chicago, IL; four-parameter logistic equation) to determine the $\mathrm{IC}_{50}$ concentration (equivalent to $\mathrm{K}_{\mathrm{i}}$ as the probe substrate concentration in the assay is at least 10 times lower than its MichaelisMenten kinetic constant $\left(K_{\mathrm{m}}\right)$ value, and assuming competitive inhibition).

\section{Assessment of Telithromycin as a Reversible or Time-Dependent Inhibitor} of CYP3A4 by IC $_{50}$ Shift Assay

Six concentrations of telithromycin $(0.4,1,4,10,40$, and $100 \mu \mathrm{M}$; final DMSO concentration, $0.25 \% \mathrm{v} / \mathrm{v}$ ) and pooled human liver microsomes (final concentration, $0.1 \mathrm{mg} / \mathrm{ml})$ were either preincubated at $37^{\circ} \mathrm{C}$ in $0.1 \mathrm{M}$ phosphate buffer $(\mathrm{pH}$ 7.4) for 30 minutes in the absence and presence of NADPH (1 mM) or underwent no preincubation (termed 0 -minute preincubation). At the end of the preincubation period, the CYP3A4 probe substrate midazolam $\left(2.5 \mu \mathrm{M}\right.$; equivalent to $\left.K_{\mathrm{m}}\right)$ and NADPH $(1 \mathrm{mM}$ ) were then added (final DMSO concentration, $0.26 \% \mathrm{v} / \mathrm{v}$ ), and 
the samples were incubated for 5 minutes at $37^{\circ} \mathrm{C}$. The time-dependent inhibitor mifepristone $(0.2,0.5,2,5,20$, and $50 \mu \mathrm{M})$ was incubated alongside telithromycin as a positive control. Incubations were performed in singlicate wells per condition.

After the incubation period, reactions were terminated by the addition of two volumes of ice-cold methanol and subsequently centrifuged at $1400 \mathrm{~g}$ for 30 minutes at $4^{\circ} \mathrm{C}$ to remove precipitated protein. An aliquot $(40 \mu 1)$ of each supernatant was transferred to a 96-well Abgene plate containing $0.1 \%(\mathrm{v} / \mathrm{v})$ aqueous formic acid and an internal standard (metoprolol) solution $(60 \mu \mathrm{l})$. The formation of the metabolite 1-hydroxymidazolam was monitored by peak area response (using metoprolol as an internal standard) by liquid chromatographytandem mass spectrometry in positive-ion mode using a parent-to-daughter transition of 342.108-203.045, as described below. Metabolite peak area response in the presence of telithromycin was converted to a percentage of (vehicle) control activity, which was subsequently plotted against nominal inhibitor concentration and fitted using WinNonLin (model 103 with the Levenburg-Marquardt algorithm) to determine the $\mathrm{IC}_{50}$ concentration.

\section{Assessment of Telithromycin as a Reversible Inhibitor of CYP3A4 $\left(\mathrm{K}_{\mathrm{i}}\right.$ Determination)}

Six concentrations of telithromycin $(1,2.5,5,10,25$, and $50 \mu \mathrm{M}$; equivalent to approximately $0.1 \times \mathrm{IC}_{50}, 0.25 \times \mathrm{IC}_{50}, 0.5 \times \mathrm{IC}_{50}, 1 \times \mathrm{IC}_{50}, 2.5 \times \mathrm{IC}_{50}$, and $5 \times$ $\mathrm{IC}_{50}$ ) were preincubated for 5 minutes at $37^{\circ} \mathrm{C}$ in $0.1 \mathrm{M}$ phosphate buffer $(\mathrm{pH} 7.4)$ containing pooled human liver microsomes (final concentration, $0.1 \mathrm{mg} / \mathrm{ml}$ ) and the CYP3A4 probe substrate midazolam at five different concentrations $(0.75$, $2.5,5,10$, and $15 \mu \mathrm{M}$; equivalent to approximately $0.3 \times K_{\mathrm{m}}, 1 \times K_{\mathrm{m}}, 2 \times K_{\mathrm{m}}$, $4 \times K_{\mathrm{m}}$, and $\left.6 \times K_{\mathrm{m}}\right)$. After the preincubation period, reactions were initiated by the addition of NADPH $(1 \mathrm{mM})$, and incubated for 30 minutes (final DMSO concentration, $0.3 \% \mathrm{v} / \mathrm{v})$. A vehicle control incubation containing DMSO instead of telithromycin was included with each substrate concentration, and a positive control inhibitor, ketoconazole $(0.008,0.02,0.04,0.06,0.08$, and $0.2 \mu \mathrm{M}$; equivalent to approximately $0.1 \times \mathrm{IC}_{50}, 0.25 \times \mathrm{IC}_{50}, 0.5 \times \mathrm{IC}_{50}, 0.75 \times \mathrm{IC}_{50}, 1 \times$ $\mathrm{IC}_{50}$, and $2.5 \times \mathrm{IC}_{50}$ ), was incubated alongside. Incubations were performed in duplicate wells per condition on three separate occasions.

After the incubation period, reactions were terminated, processed, and analyzed for the metabolite 1-hydroxymidazolam as described above ( $\mathrm{IC}_{50}$ shift). Regression analysis of enzyme kinetic data (based on metabolite peak area response) was carried out using the Enzyme Kinetics module of SigmaPlot 12.5, using models for competitive, noncompetitive, uncompetitive, and mixed inhibition according to the equations displayed in Table 1 . The $\mathrm{K}_{\mathrm{i}}$ value of telithromycin was determined using each inhibition type model. The goodness-of-fit criteria used to select the most appropriate inhibition model was composed of visual inspection of the data $\left(K_{\mathrm{m}}\right.$, Eadie-Hofstee, and Lineweaver-Burk plots), squared correlation coefficient $\left(R^{2}\right)$, and corrected Akaike information criterion (AICc).

\section{Inactivation of CYP3A4 by Telithromycin ( $K_{I}$ and $k_{\text {inact }}$ determinations)}

The concentration ranges of inhibitor, preincubation times, and dilution factor were determined from the reversible inhibition- and time-dependent inhibition assays conducted above. Seven concentrations of telithromycin $(0.4,0.8,2,4,8$, 20 , and $40 \mu \mathrm{M})$ or the positive control mifepristone $(0.2,0.4,1,2,4,10$, and $20 \mu \mathrm{M})$, plus a vehicle control $(0.25 \% \mathrm{v} / \mathrm{v}$ DMSO in preincubation) were preincubated in $0.1 \mathrm{M}$ phosphate buffer $(\mathrm{pH} 7.4)$ at $37^{\circ} \mathrm{C}$ containing human liver microsomes $(0.1 \mathrm{mg} / \mathrm{ml})$ and NADPH $(1 \mathrm{mM})$ for a range of five preincubation times $(5,10,15,20$, and 30 minutes) plus a 0 -minute preincubation, in duplicate wells and on three separate occasions. At the end of the individual preincubations, an aliquot of the preincubation mixture was added to an incubation mixture, in a 1: 10 dilution, with the specific CYP3A4 probe substrate midazolam $(12.5 \mu \mathrm{M}$, equivalent to $\left.5 \times K_{\mathrm{m}}\right)$ and $\mathrm{NADPH}(1 \mathrm{mM})$ for a 5 -minute incubation at $37^{\circ} \mathrm{C}$ (final DMSO concentration, $0.075 \% \mathrm{v} / \mathrm{v}$; final microsomal concentration, $0.01 \mathrm{mg} / \mathrm{ml}$ ). This procedure diluted telithromycin to one-tenth of its original concentration to reduce any impact of reversible inhibition on CYP3A4. After the incubation period, reactions were terminated, processed, and analyzed for the metabolite 1-hydroxymidazolam, as described above ( $\mathrm{IC}_{50}$ shift).

The decrease in the formation of the metabolite compared with the vehicle control at each preincubation time was used to calculate the maximal rate of inactivation of enzyme ( $\left.\mathrm{k}_{\text {inact }}\right)$ and the inhibitor concentration that causes halfmaximal inactivation of enzyme $\left(\mathrm{K}_{\mathrm{I}}\right)$. Briefly, the average activity remaining was determined at each telithromycin/mifepristone concentration as a percentage of the vehicle control activity for the specific preincubation time to account for any loss of metabolic activity over time. The natural logarithm of the corrected percent remaining activity was then plotted versus the preincubation time for each inhibitor concentration, and linear least-squares regression enabled the inactivation rate constant $\left(\mathrm{k}_{\mathrm{obs}}\right.$; the observed initial rate of inactivation for each inhibitor concentration) to be calculated. Nonlinear regression analysis of the $\mathrm{k}_{\mathrm{obs}}$ data versus the preincubation inhibitor concentration was performed using the Enzyme Kinetics module of SigmaPlot 12.5 to determine $k_{\text {inact }}$ and $K_{I}$ values from the modified Michaelis-Menten equation:

$$
\mathrm{k}_{\mathrm{obs}}=\frac{\mathrm{k}_{\text {inact }} \cdot[\mathrm{I}]}{\left(\mathrm{K}_{\mathrm{I}}+[\mathrm{I}]\right)}
$$

where $\mathrm{k}_{\text {inact }}$ is analogous to $V_{\max },[\mathrm{I}]$ is the inhibitor concentration, and $\mathrm{K}_{\mathrm{I}}$ is analogous to $K_{\mathrm{m}}$.

\section{Liquid Chromatography-Mass Spectrometry}

The system consisted of an Acquity Binary Solvent Manager, Acquity 4-position heated column manager, 2777 Ultra High Pressure Autosampler, and a Xevo-TQ MS Triple Quadrupole Mass Spectrometer (Waters Ltd., Hertsfordshire, UK). 1-Hydroxymidazolam was resolved on an Acquity HSS T3 $(1.8 \mu \mathrm{m})$ column $(2.1 \times 30 \mathrm{~mm}$; Waters Ltd. $)$ at $40^{\circ} \mathrm{C}$ with a gradient of methanol $(0-95-$ $95 \%, 0-0.6-0.65$ minute) in $0.1 \%$ (v/v) aqueous formic acid containing $10 \mathrm{mM}$ ammonium formate. The flow rate was $1 \mathrm{ml} / \mathrm{min}$. Nitrogen was used as the nebulizing gas. The source temperature was $150^{\circ} \mathrm{C}$, the desolvation temperature was $650^{\circ} \mathrm{C}$, and the cone voltage and collision energy were $35 \mathrm{~V}$ and $30 \mathrm{eV}$, respectively. Data were processed with TargetLynx XS MassLynx 4.1 software (Waters Ltd.). Consistent with the published literature (Zimmerlin et al., 2011), the formation of 1-hydroxymidazolam in the assays was monitored by peak area response. This gave acceptable dynamic detection ranges, determined by mean analyte signal-to-noise ratio above background mass spectroscopy response in the presence of maximal inhibition with the positive control inhibitor compared with the uninhibited (vehicle control) condition, corresponding to 674-6364 (for $0.75 \mu \mathrm{M}$ midazolam incubations) and $3561-15,357$ (for $15 \mu \mathrm{M}$ midazolam incubations) for reversible inhibition experiments, or 290-2841 for timedependent inhibition experiments

TABLE 1

Determined in vitro inhibitory kinetic parameters of telithromycin vs. OATP1B1 and CYP3A4

\begin{tabular}{lllllllr}
\hline \multirow{2}{*}{ Type } & \multicolumn{6}{c}{ Determined Inhibitory Kinetic Parameter Values } \\
\cline { 2 - 8 } & Expt 1 & Expt 2 & Expt 3 & Mean & \multicolumn{1}{c}{ S.D. } & CV $(\%)$ & \multicolumn{1}{c}{$95 \% \mathrm{Cl}^{a}$} \\
\hline OATP1B1 $\mathrm{K}_{\mathrm{i}}\left(\mathrm{IC}_{50}\right)(\mu \mathrm{M})$ & 13.7 & 11.3 & 11.1 & 12.0 & 1.45 & 12.1 & $8.40-15.6$ \\
CYP3A4 $\mathrm{K}_{\mathrm{i}}(\mu \mathrm{M})$ & 3.68 & 4.29 & 2.99 & 3.65 & 0.531 & 14.5 & $2.33-4.97$ \\
CYP3A4 $\mathrm{K}_{\mathrm{I}}(\mu \mathrm{M})$ & 1.15 & 0.786 & 1.20 & 1.05 & 0.226 & 21.5 & $0.489-1.61$ \\
CYP3A4 $\mathrm{k}_{\text {inact }}\left(\mathrm{min}_{-1}\right)$ & 0.02492 & 0.03036 & 0.02790 & 0.02772 & 0.00272 & 9.8 & $0.02096-0.03448$
\end{tabular}

$\mathrm{K}_{\mathrm{i}}$ vs. the enzyme or transporter (for OATP1B1; assuming competitive inhibition, this equates to the $\mathrm{IC}_{50}$ value in the assay as the probe substrate concentration used is much lower than the $K_{\mathrm{m}}$ value). CI, confidence interval; Expt, experiment.

${ }^{a} 95 \%$ CI was calculated by adding or subtracting the product of the $t$ distribution value (4.303) and the value of the S.D. divided by the square root of the sample size from the determined mean value. 
Mechanistic Static Prediction of Simvastatin Acid AUC Change for the Known Clinical DDI Perpetrated by Telithromycin Based upon Determined In Vitro OATP1B1 and CYP3A4 Inhibitory Parameters

The mean OATP1B1 $\mathrm{IC}_{50}$ (equating to $\mathrm{K}_{\mathrm{i}}$ ) and CYP3A4 $\mathrm{K}_{\mathrm{i}}$ and $\mathrm{K}_{\mathrm{I}} / \mathrm{k}_{\text {inact }}$ values obtained for telithromycin were incorporated into the adapted Rowland-Matin mechanistic static equation previously described by Elsby et al. $(2012,2016)$ for reversible inhibition (eq. 1), but which has subsequently been modified to include a time-dependent inhibition component for $\mathrm{P} 450$ enzymes (eq. 3), to predict the change in simvastatin acid AUC based upon inhibition of an OATP1B $1 f_{\mathrm{e}}$ value of 0.79 , and $f_{\mathrm{m}}$ values of 0.40 and 0.83 for intestinal and hepatic CYP3A4, respectively (Elsby et al., 2012).

Reversible Inhibition.

$$
\mathrm{AUCR}=\frac{1}{\frac{f_{\mathrm{m} / \mathrm{e}}}{\left(1+\left[\mathrm{I} / \mathrm{K}_{\mathrm{i}}\right)\right.}+\left(1-f_{\mathrm{m} / \mathrm{e}}\right)}
$$

where $\mathrm{K}_{\mathrm{i}}$ equates with $\mathrm{IC}_{50}$ for transporters if the probe substrate concentration [S] $<<<<K_{\mathrm{m}}$ in the transporter inhibition assay and assuming competitive inhibition, based on the equation by Cheng and Prusoff (1973); and [I] is the unbound maximum hepatic inlet concentration $\left[\mathrm{I}_{\text {in max u }}=\mathrm{f}_{\mathrm{u}} \times\left(C_{\max }+\left(\left(\mathrm{F}_{\mathrm{a}} \mathrm{F}_{\mathrm{g}} \times\right.\right.\right.\right.$ $\mathrm{k}_{\mathrm{a}} \times$ dose $($ moles $\left.\left.\left.\left.)\right) / \mathrm{Q}_{\mathrm{h}}\right)\right) / \mathrm{R}_{\mathrm{B}}\right]$ for hepatic transporters/enzymes, or $[\mathrm{I}]$ is maximum enterocyte concentration $\left(I_{g}=\left(F_{a} F_{g} \times k_{a} \times\right.\right.$ dose (moles) $\left.) / Q_{\text {ent }}\right)$ for intestinal transporters/enzymes (Elsby et al., 2016), where $f_{u}$ is the unbound fraction in plasma, $\mathrm{F}_{\mathrm{a}} \mathrm{F}_{\mathrm{g}}$ is the fraction of the dose absorbed after oral administration, $\mathrm{k}_{\mathrm{a}}$ is the absorption rate constant $\left(\min _{-1}\right), Q_{h}$ is the hepatic blood flow $(1500 \mathrm{ml} / \mathrm{min}), R_{B}$ is the blood-to-plasma concentration ratio (default, 1.0), and $\mathrm{Q}_{\text {ent }}$ is enterocyte blood flow $(300 \mathrm{ml} / \mathrm{min})$.

Time-Dependent Inhibition $\mathbf{R}_{2}$ Value.

$$
\begin{aligned}
\mathrm{R}_{2} & =\frac{\mathrm{k}_{\mathrm{obs}}+\mathrm{k}_{\mathrm{deg}}}{\mathrm{k}_{\mathrm{deg}}} \\
\mathrm{k}_{\mathrm{obs}} & =\frac{\mathrm{k}_{\text {inact }} \times[\mathrm{I}]}{\mathrm{K}_{\mathrm{I}}+[\mathrm{I}]} \\
\mathrm{R}_{2} & =\frac{\frac{\mathrm{k}_{\text {inac }} \times[\mathrm{I}]}{\mathrm{K}_{\mathrm{I}}+[\mathrm{I}]}+\mathrm{k}_{\mathrm{deg}}}{\mathrm{k}_{\mathrm{deg}}}
\end{aligned}
$$

Reversible and Time-Dependent Enzyme Inhibition.

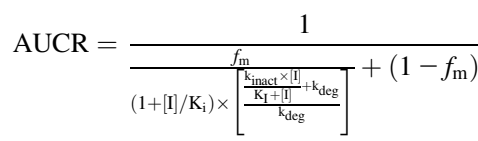

where $\mathrm{k}_{\mathrm{obs}}$ is the observed (apparent first order) inactivation rate constant of the affected enzyme, $\mathrm{k}_{\mathrm{deg}}$ is the apparent first-order degradation constant of the affected enzyme [intestinal CYP3A4 $=0.00048$ per minute (Fahmi et al., 2009); hepatic CYP3A4 $=0.00032$ per minute (Obach et al., 2007)]

\section{Results}

Assessment of Telithromycin as an Inhibitor of OATP1B1 In Vitro. Telithromycin demonstrated reproducible interassay concentration-dependent inhibition of OATP1B1-mediated transport of $\left[{ }^{3} \mathrm{H}\right]$-estradiol $17 \beta$-D-glucuronide $(0.02 \mu \mathrm{M})$ with a mean \pm S.D. $\mathrm{IC}_{50}$ value of $12.0 \pm 1.45 \mu \mathrm{M}$ (Fig. 1; Table 1). The assessment of DDI potential via inhibition of hepatic OATP1B1 using the current (http://www.fda.gov/ downloads/Drugs/GuidanceComplianceRegulatoryInformation/Guidances/ UCM581965.pdf) static equation approach gave an $\mathrm{R}=1+\left[\mathrm{I}_{\text {in } \max u}\right] / \mathrm{K}_{\mathrm{i}}$ value of $1.21(>1.1)$, indicating the potential for interaction in vivo (Table 3, for the $[\mathrm{I}]$ value). The positive control inhibitor, rifamycin SV $(100 \mu \mathrm{M})$ gave acceptable inhibition (mean $95.1 \%$ ) in the test system.

Assessment of Telithromycin as a Reversible or Time-Dependent Inhibitor of CYP3A4 In Vitro ( IC $_{50}$ Shift). CYP3A4-mediated metabolism of midazolam $\left(2.5 \mu \mathrm{M} \equiv K_{\mathrm{m}}\right)$ was inhibited by telithromycin in a concentration-dependent manner with $\mathrm{IC}_{50}$ values of $9.32,10.4$, or $3.68 \mu \mathrm{M}$ after a 0 -minute preincubation, a 30 -minute

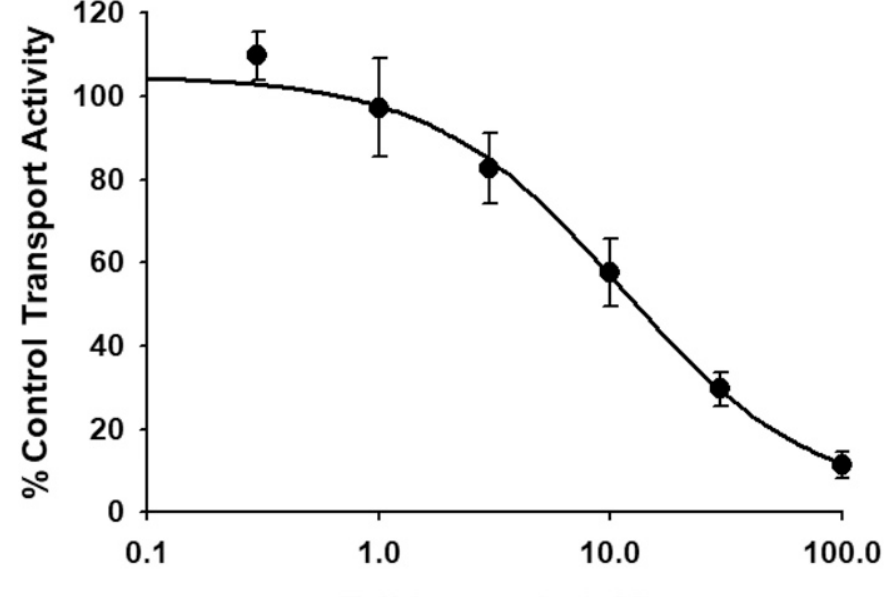

Telithromycin $(\mu \mathrm{M})$

Fig. 1. Representative plot of mean concentration-dependent inhibition of OATP1B1mediated transport of $\left[{ }^{3} \mathrm{H}\right]$-estradiol $17 \beta$-D-glucuronide $(0.02 \mu \mathrm{M})$ by telithromycin. Data are expressed as the mean \pm S.D. from triplicate wells per incubation condition.

preincubation in the absence of NADPH, or a 30-minute preincubation in the presence of NADPH, respectively. The 2.83-fold shift (decrease) in $\mathrm{IC}_{50}$ value after metabolic preincubation confirmed that telithromycin was both a reversible and time-dependent inhibitor of CYP3A4.

The positive control inhibitor mifepristone inhibited with $\mathrm{IC}_{50}$ values of 6.66 and 6.12 or $0.898 \mu \mathrm{M}$ without (0 minute or minus NADPH), or with a metabolic preincubation, respectively. The 6.81 -fold shift in $\mathrm{IC}_{50}$ value confirmed that the in vitro test system was able to detect both reversible and time-dependent inhibitors of CYP3A4.

Assessment of Telithromycin as a Reversible Inhibitor of CYP3A4 In Vitro ( $\mathbf{K}_{\mathbf{i}}$ Determination). Telithromycin demonstrated reproducible interassay concentration-dependent inhibition of midazolam-1 hydroxylation in pooled human liver microsomes of a type that was determined to be of a competitive inhibitory nature with a mean \pm S.D. $\mathrm{K}_{\mathrm{i}}$ of $3.65 \pm 0.531 \mu \mathrm{M}$ (Fig. 2; Table 1), based on the rank ordering of the type of inhibition by goodness-of-fit criteria as described above and shown in Table 2. Due to the low microsomal protein concentration used in the assay, microsomal binding in the test system was considered to be negligible. Assessment of DDI potential via reversible inhibition of intestinal or hepatic CYP3A4 using the current (http://www.fda.gov/downloads/Drugs/GuidanceComplianceRegulatoryInformation/Guidances/UCM581965.pdf) static equation approach gave $\mathrm{R}_{1, \text { gut }}=1+\left[\mathrm{I}_{\text {gut }}\right] / \mathrm{K}_{\mathrm{i}}$ or $\mathrm{R}_{1}=1+\left[\mathrm{I}_{\max } \mathrm{u}\right] / \mathrm{K}_{\mathrm{i}}$ values of $1081(>11)$ or $1.26(>1.02)$, respectively, indicating the potential for interaction in vivo (Table $3,[\mathrm{I}]$ values). The positive control inhibitor ketoconazole fitted within acceptance criteria with a determined mean ( \pm S.D.) $\mathrm{K}_{\mathrm{i}}$ of $0.0248 \pm 0.00254 \mu \mathrm{M}$, using a noncompetitive inhibition model.

Inactivation of CYP3A4 by Telithromycin $\left(K_{I}\right.$ and $k_{\text {inact }}$ Determinations). Telithromycin demonstrated both reproducible interassay time- and concentration-dependent inactivation of CYP3A4 activity (Fig. 3; Table 1) with a determined mean \pm S.D. $\mathrm{k}_{\text {inact }}$ value of $0.02772 \pm 0.00272 \mathrm{~min}_{-1}$, a mean \pm S.D. $\mathrm{K}_{\mathrm{I}}$ value of $1.05 \pm 0.226 \mu \mathrm{M}$, and a mean \pm S.D. $\mathrm{k}_{\text {inac }} / \mathrm{K}_{\mathrm{I}}$ ratio of $28 \pm 9.4 \mathrm{ml} / \mathrm{min} / \mathrm{micromole}$. Due to the low microsomal protein concentration used in the assay, microsomal binding in the test system was considered to be negligible. Assessment of DDI potential via time-dependent inhibition (inactivation) of hepatic CYP3A4 using the FDA (2012) (http://www.fda.gov/downloads/Drugs/ GuidanceComplianceRegulatoryInformation/Guidances/UCM292362.pdf) static equation approach gave an $\mathrm{R}_{2}=\left(\mathrm{k}_{\mathrm{obs}}+\mathrm{k}_{\mathrm{deg}}\right) / \mathrm{k}_{\mathrm{deg}}$ value of $64(>1.25)$, 

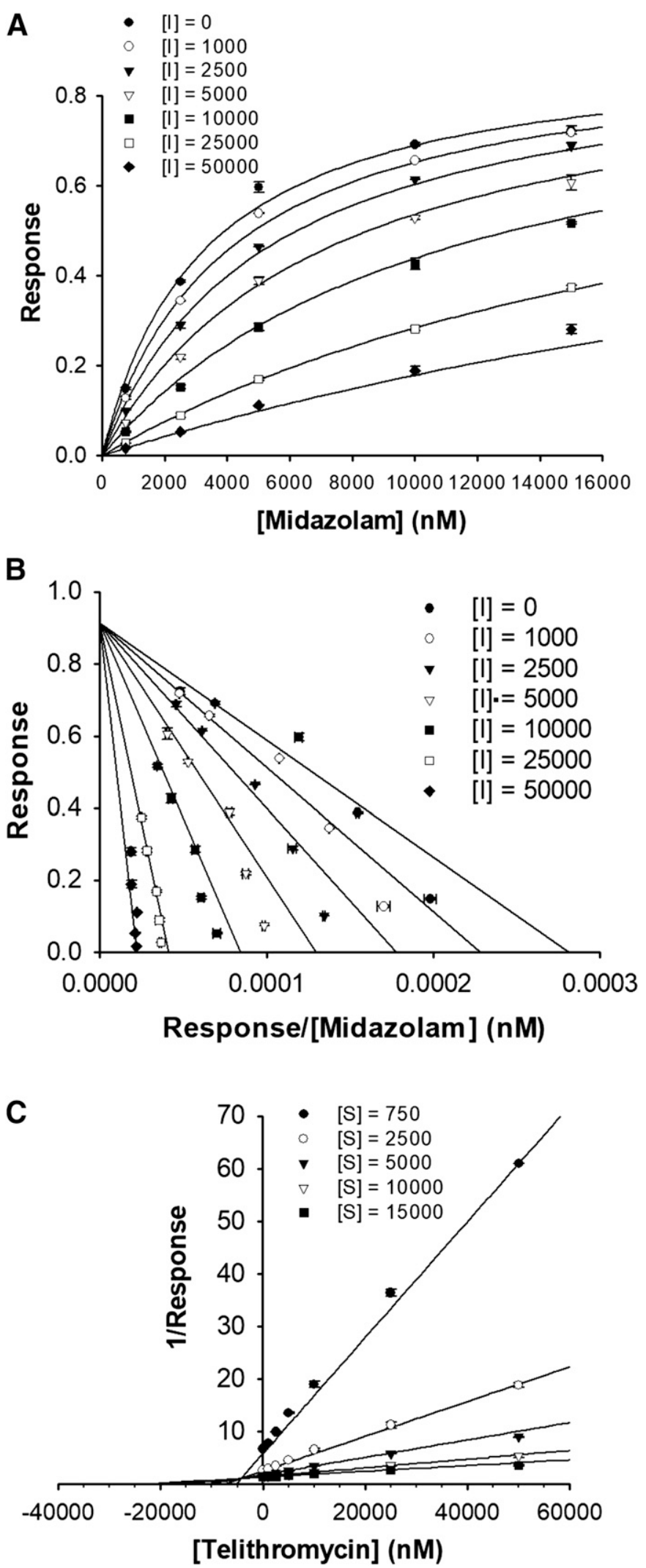

Fig. 2. Representative Michaelis-Menten plot (competitive inhibition) (A), EadieHofstee plot (competitive inhibition) (B), and Dixon plot (competitive inhibition) (C) of the effect of telithromycin on CYP3A4-mediated 1-hydroxymidazolam formation in pooled human liver microsomes. Data are expressed as the mean \pm S.E. from duplicate wells. indicating the potential for interaction in vivo (Table $3,[\mathrm{I}]$ and $\mathrm{k}_{\mathrm{deg}}$ values). The positive control inhibitor mifepristone fitted within acceptance criteria with determined mean $( \pm$ S.D. $) k_{\text {inact }}, K_{I}$, and $k_{\text {inac }} / K_{I}$ ratio values of $0.07832 \pm 0.00553 \mathrm{~min}_{-1} 0.865 \pm 0.166 \mu \mathrm{M}$ and $92 \pm 11 \mathrm{ml} / \mathrm{min} /$ micromole, respectively.

Predicted Versus Observed Simvastatin Acid AUC Changes with Telithromycin Based upon In Vitro OATP1B1 and CYP3A4 Inhibitory Data. Using the mean drug inhibitory affinities determined above for telithromycin versus OATP1B1 and CYP3A4 and its pharmacokinetic parameters provided in Table 3, calculations were performed with mechanistic static eqs. 1 and 3 to predict the theoretical fold increase in simvastatin acid AUC that would occur after either their coadministration or being administered 12 hours apart.

Upon coadministration, the calculated predicted theoretical fold increases in AUC due to the inhibition of hepatic OATP1B1, reversible inhibition of intestinal CYP3A4 and reversible inhibition of hepatic CYP3A4 were 1.16-, 1.52-, and 1.52-fold, respectively, collectively giving an overall AUCR of only 2.68. In contrast, calculated theoretical AUC increases due to time-dependent inactivation of intestinal or hepatic CYP3A4 alone were either 1.65-fold or 5.45-fold, respectively, with maximum theoretical increases being 1.67-fold or 5.88-fold if each single pathway was completely ablated in DDI. Finally, the overall predicted AUC increase due to the inhibition of OATP1B1 (1.16), combined reversible inhibition and inactivation of intestinal CYP3A4 (1.66), and combined reversible inhibition and inactivation of hepatic CYP3A4 (5.62) was 10.8-fold, which matched the clinically observed AUCR for simvastatin acid when coadministered with telithromycin (Table 4).

Upon dose staggering, using 12-hour plasma unbound concentrations of telithromycin, the calculated predicted theoretical fold increases in AUC due to the inhibition of hepatic OATP1B1, reversible inhibition of intestinal CYP3A4, and reversible inhibition of hepatic CYP3A4 were only 1.01-, 1.01-, and 1.02-fold, respectively. However, the overall predicted AUC increase due to the inactivation of intestinal (1.49-fold) and hepatic (3.60-fold) CYP3A4 was 5.4-fold, which was within $33 \%$ of the clinically observed AUCR for simvastatin acid when administered 12 hours apart from telithromycin (Table 4).

\section{Discussion}

DDIs with statins, in particular simvastatin (acid), are of clinical concern because elevated plasma concentrations of statins are linked to increased risk of myopathy (Egan and Colman, 2011). Because statins are common comedications across disease indications, it is beneficial to project teams to be able to quantify, using mechanistic static models, the predicted DDI an investigational drug might perpetrate with these victim drugs to contextualize the clinical risk (Elsby et al., 2012; Williamson and Riley, 2017). However, pivotal to such accurate prediction is that the model incorporates all mechanisms of inhibition for metabolic enzymes to avoid underprediction of the clinical situation. One such underprediction of simvastatin acid AUCR, based on the inhibition of CYP3A4 in the model, was reported previously for the DDI with telithromycin (Elsby et al., 2012). To reconcile this difference between prediction and the clinic, telithromycin was investigated in this study as a reversible and time-dependent inhibitor of CYP3A4 in vitro, alongside inhibition determined versus OATP1B1. The resulting inhibitory parameters were input into the mechanistic static model, newly modified to incorporate a time-dependent inhibition component for $\mathrm{P} 450$, to ensure that the model now described the complete enzyme inhibition potential to reproduce the clinically observed DDI with telithromycin, thereby ensuring the provision of more accurate prediction during future routine application with new drugs in the model. 
TABLE 2

Determination of $\mathrm{K}_{\mathrm{i}}$ and observed fit to different inhibition models for the inhibition of CYP3A4-mediated 1-hydroxylation of midazolam by telithromycin in pooled human liver microsomes

\begin{tabular}{|c|c|c|c|c|c|c|c|c|c|c|}
\hline \multirow{2}{*}{ Inhibition Type } & \multirow{2}{*}{ Rate Equation } & \multicolumn{3}{|c|}{ Experiment 1} & \multicolumn{3}{|c|}{ Experiment 2} & \multicolumn{3}{|c|}{ Experiment 3} \\
\hline & & $\mathrm{K}_{\mathrm{i}}$ & $R^{2}$ & $\mathrm{AICc}$ & $\mathrm{K}_{\mathrm{i}}$ & $R^{2}$ & $\mathrm{AICc}$ & $\mathrm{K}_{\mathrm{i}}$ & $R^{2}$ & $\mathrm{AICc}$ \\
\hline & & $\mu \mathrm{M}$ & & & $\mu \mathrm{M}$ & & & $\mu \mathrm{M}$ & & \\
\hline Competitive & $\mathrm{v}=\frac{\mathrm{Vmax}[\mathrm{S}]}{[\mathrm{S}]+\mathrm{K}_{\mathrm{m}}\left(1+\frac{\mathrm{II}}{\mathrm{K}_{\mathrm{i}}}\right)}$ & 3.68 & 0.989 & -515 & 4.29 & 0.994 & -563 & 2.99 & 0.988 & -439 \\
\hline Noncompetitive & $\mathrm{v}=\frac{\mathrm{Vmax}[\mathrm{S}]}{\mathrm{K}_{\mathrm{m}}\left(1+\frac{[\mathrm{II}}{\mathrm{K}_{\mathrm{i}}}\right)+[S]\left(1+\frac{[I]}{K_{i}}\right)}$ & 16.9 & 0.974 & -453 & 16.8 & 0.975 & -458 & 14.1 & 0.968 & -371 \\
\hline Uncompetitive & $\mathrm{V}=\frac{\mathrm{Vmax}[\mathrm{S}]}{\mathrm{K}_{\mathrm{m}}+[\mathrm{S}]\left(1+\frac{[\mathrm{I}}{\mathrm{K}_{\mathrm{i}}}\right)}$ & 11.0 & 0.945 & -399 & 10.1 & 0.943 & -400 & 9.07 & 0.935 & -322 \\
\hline $\operatorname{Mixed}^{a}$ & $\mathrm{v}=\frac{\mathrm{Vmax}[\mathrm{S}]}{\mathrm{K}_{\mathrm{m}}\left(1+\frac{[I]}{\mathrm{K}_{\mathrm{K}}}\right)+[S]\left(1+\frac{[!]}{\alpha K_{\mathrm{i}}}\right)}$ & 4.33 & 0.990 & -516 & 4.29 & 0.994 & -561 & 3.10 & 0.988 & -437 \\
\hline
\end{tabular}

$\mathrm{v}$, rate of metabolite formation.

${ }^{a} \alpha$-Value for mixed inhibition determined to be 26.9, 15.6, and 151 for experiments 1,2 and 3, respectively.

For simvastatin acid, active uptake ( $86 \%$ ) into the liver is mediated by the critical OATP1B1 pathway (Elsby et al., 2012). In the present study, the determined mean OATP1B1 $\mathrm{IC}_{50}$ for telithromycin versus estradiol $17 \beta$-D-glucuronide is approximately 10 -fold more potent than previously reported versus sulfobromophthalein (Seithel et al., 2007), which was used in the earlier prediction (Elsby et al., 2012). This value is likely to be the most relevant as it has been derived 1) using a probe demonstrated to be a good OATP1B1 surrogate probe substrate for statins (Sharma et al., 2012; Izumi et al., 2015) and 2) after a 15-minute preincubation step with inhibitor to take into account any time dependency required for the in vitro test system. For this determined $\mathrm{IC}_{50}$ value, even though the $\mathrm{R}$ value is greater than the current Food and Drug Administration guidance cutoff (1.1), it is less than 1.25, which would be considered bioequivalent, suggesting that any interaction via inhibition of OATP1B1 in vivo is likely to have a minimal effect. Indeed, taking into account the OATP1B $1 f_{\mathrm{e}}$, mechanistic static modeling predicted a minimal 1.16-fold increase in AUCR due to telithromycin coadministration, effectively confirming that the inhibition of OATP1B1 would not be significant enough to impact simvastatin acid entry into hepatocytes or its availability at CYP3A4 (i.e., no impact on $f_{\mathrm{m}}$ value).

The remaining critical disposition pathways of simvastatin acid include metabolism by intestinal and hepatic CYP3A4 (Elsby et al., 2012). Equivalent $\mathrm{IC}_{50}$ values determined from both the 0 -minute preincubation and the 30-minute preincubation in the absence of NADPH confirmed telithromycin as a reversible inhibitor of CYP3A4 using the sensitive clinical probe midazolam. The reversible $\mathrm{IC}_{50}$ value obtained in the shift assay was comparable to the $15 \mu \mathrm{M}$ reported previously in recombinant CYP3A4 microsomes (Yoshida et al., 2012). According to the ordering of inhibition type by goodness-of-fit criteria, the reversible inhibition type was determined to be competitive, which is supported by the fact that the determined $\mathrm{K}_{\mathrm{i}}$ value was about half the $\mathrm{IC}_{50}$ value obtained from incubations using midazolam at a concentration equivalent to its $K_{\mathrm{m}}$ value (Cheng and Prusoff, 1973). The in vitro test system was able to define correctly the mechanism of inhibition as demonstrated by the results for the positive control ketoconazole whose inhibitor type and mean $\mathrm{K}_{\mathrm{i}}$ value were consistent with literature data (Gibbs et al., 1999). Based on reversible CYP3A4 inhibition and determined $R_{1}$ values, telithromycin has the potential to cause a DDI via intestinal and hepatic CYP3A4 perturbation, thereby increasing the bioavailability of CYP3A4 substrate drugs by reducing their first-pass metabolism.

Further to this, the $\mathrm{IC}_{50}$ shift assay also revealed telithromycin to be a time-dependent inhibitor of CYP3A4 based on the 2.83-fold decrease in $\mathrm{IC}_{50}$ after metabolic preincubation. The in vitro test system was suitable for such assessment as confirmed by the large shift observed for the positive control mifepristone and its determined mean $\mathrm{K}_{\mathrm{I}}$ and $\mathrm{k}_{\text {inact }}$ values, which were consistent with literature data (He et al., 1999). Although the $k_{\text {inact }} / K_{I}$ ratio for the inactivation of CYP3A4 by telithromycin was approximately three times lower than the in vitro inactivation potency of mifepristone, the basic $R_{2}$ equation ratio (64) indicated a large potential for interaction in vivo based on this mechanism for telithromycin. To our knowledge, this is the first reported in vitro study to demonstrate that telithromycin is a time-dependent inhibitor of CYP3A4.

TABLE 3

Pharmacokinetic parameters of telithromycin in clinical interaction studies with simvastatin acid

\begin{tabular}{|c|c|c|c|c|c|c|c|c|}
\hline Perpetrator Drug & Dose & MW & {$\left[\mathrm{I}_{\mathrm{g}}\right]$} & {$\left[C_{\max }\right]$ or $\left[\mathrm{C}_{12 \mathrm{~h}}\right]$} & $f_{u}$ & {$\left[\begin{array}{lll}\mathrm{C}_{12 \mathrm{~h}} & \mathrm{u}\end{array}\right]$} & {$\left[\mathrm{I}_{\text {in } \max }\right]$} & {$\left[I_{\text {in } \max } u\right]$} \\
\hline & $m g$ & & & $\mu \mathrm{M}$ & & & $\mu \mathrm{M}$ & \\
\hline Telithromycin (coadministered) & 800 & 812 & 22.5 & 2.76 & 0.35 & NA & 7.25 & 2.538 \\
\hline Telithromycin (12 h apart) & 800 & 812 & NA & 0.246 & 0.35 & 0.086 & NA & NA \\
\hline
\end{tabular}

$\left[\mathrm{C}_{12} \mathrm{~h}\right]$, Plasma concentration for total (bound plus unbound) drug at $\mathrm{T}=12 \mathrm{~h}(0.2 \mathrm{mg} / \mathrm{l})$ measured in the clinical interaction study with simvastatin acid (Study Number 1048, HMR3647 AUC profile; Ketek FDA approval package review 4); $C_{\max }$ ], $C_{\max }$ for total [bound plus unbound) drug measured in the clinical interaction study with simvastatin acid (Study Number 1048; Ketek FDA approval package review 4 (Clinical Pharmacology Biopharmaceutics Review Part 4, accessed via Drugs@FDA database; www.accessdata.fda.gov/drugsatfda_docs/ nda/2004/21-144_Ketek_BioPharmr_P4.pdf)]; $\mathrm{f}_{\mathrm{u}}$, median fraction unbound [taken from the Ketek drug label accessed via Drugs@FDA database; www.accessdata.fda.gov/drugsatfda_docs/label/2010/021144s014lbl.pdf]; [ $\left.\mathrm{I}_{\mathrm{g}}\right]$, maximal enterocyte concentration; $\left[\mathrm{I}_{\text {in }} \max \right]$, maximum hepatic inlet concentration; calculated as described in Materials and Methods using telithromycin-specific values of $\mathrm{F}_{\mathrm{a}} \mathrm{F}_{\mathrm{g}}=0.57$ (www.accessdata.fda.gov/drugsatfda_docs/label/2010/021144s014lbl.pdf) and $\mathrm{k}_{\mathrm{a}}=0.012 \mathrm{~min}(0.740 \mathrm{~h})$ (Ikawa et al., 2014). NA, not applicable to DDI. 
A

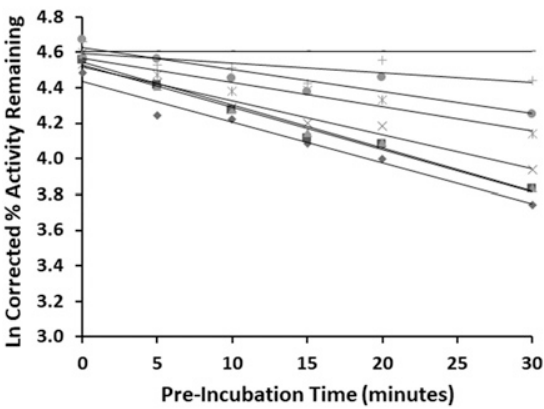

B

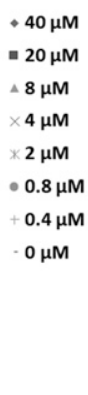

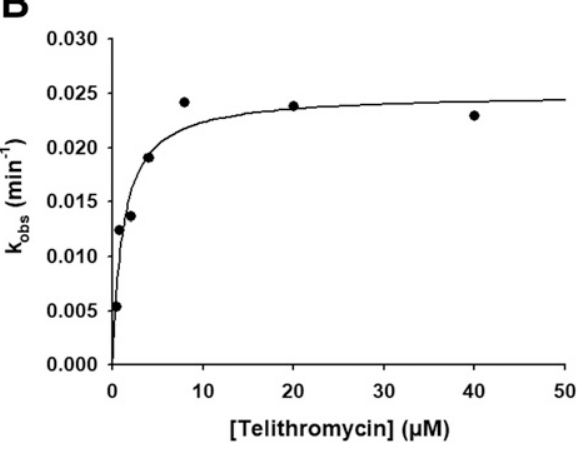

Fig. 3. (A) Representative plot of natural logarithm of the corrected percentage CYP3A4 activity remaining against preincubation time based on the effect of telithromycin on 1-hydroxymidazolam formation in pooled human liver microsomes. (B) Nonlinear (Michaelis-Menten) regression plot of the observed rates of enzyme inactivation against inhibitor concentration for telithromycin. Data are expressed as the mean from duplicate wells.
Using mechanistic modeling, the predicted overall simvastatin acid AUCR (2.68) due to reversible inhibition of intestinal/hepatic CYP3A4 and inhibition of OATP1B1 in this study was lower than previously reported (4.0; Elsby et al., 2012). Reasons for this include the following: differences between $\mathrm{F}_{\mathrm{a}} \mathrm{F}_{\mathrm{g}}$ and $\mathrm{k}_{\mathrm{a}}$ parameters in the current analysis (that uses telithromycin-specific parameters 0.57 and 0.012 ) compared with the original analysis (that used default conservative values of 1.0 and 0.1 ,

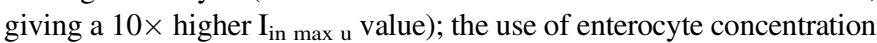
( $\mathrm{I}_{\mathrm{g}}$ ) and $f_{\mathrm{m}}$ for intestinal CYP3A4 (based on the study by Elsby et al., 2016) in this analysis, rather than the previous assumption of complete intestinal inhibition, and therefore maximal absorption, when intestinal luminal concentration $/ K_{\mathrm{i}}>10$ (Elsby et al., 2012). The absolute bioavailability value for telithromycin is considered to be equivalent to $\mathrm{F}_{\mathrm{a}} \mathrm{F}_{\mathrm{g}}$ based on investigations in the rat, which established that the high firstpass metabolism of telithromycin is intestinally mediated and not due to hepatic extraction (Lee and Lee, 2007). The use of such drug-specific parameters is favored because it enables better predictability. Although reversible inhibition of intestinal CYP3A4 is predicted to almost completely inhibit that pathway after coadministration with telithromycin, the impact of hepatic inhibition is only predicted to be marginal (1.52-fold; 52\% AUC increase compared with a theoretical maximum 488\%, representing only approximately $10 \%$ of total activity). In contrast, reversible inhibition of intestinal/hepatic CYP3A4 (and of OATP1B1) is predicted to be negligible when the drugs are administered 12 hours apart due to minimal telithromycin systemic plasma concentrations.

This analysis indicates time-dependent inhibition of CYP3A4 by telithromycin as the primary driver of observed DDIs with simvastatin acid. To confirm this, the previous mechanistic static model (Elsby et al.,
2012, 2016) was modified to incorporate an enzyme inactivation component capturing parameters $\mathrm{k}_{\text {inact }}, \mathrm{K}_{\mathrm{I}}$, and $\mathrm{k}_{\mathrm{deg}}$ for intestinal or hepatic CYP3A4, as detailed in eq. 3. Using this modified model, it is clear that telithromycin-mediated inactivation of intestinal and hepatic CYP3A4 alone results in almost complete ablation of these simvastatin acid disposition pathways based on predictions of AUCR after their coadministration, when compared with the theoretical AUCR maximum for each single pathway. Moreover, when the major effect of CYP3A4 inactivation is combined with the modest effect of reversible CYP3A4 inhibition and OATP1B1 inhibition, the overall predicted fold increase in simvastatin acid AUC (10.8-fold) matched the clinically observed AUC increase (10.8-fold; $980 \%$ in study 1048 , www.accessdata.fda.gov/ drugsatfda_docs/nda/2004/21-144_Ketek_BioPharmr_P4.pdf). Additionally, the predicted AUCR after dose staggering was consistent with the clinical AUCR, indicating CYP3A4 inactivation as the sole mechanism underlying that DDI.

The predictability of the model was evaluated further using drugspecific parameters for another perpetrator clarithromycin $(500 \mathrm{mg})$, which is known to cause DDI with simvastatin acid, resulting in a mean 11.6-fold increase in victim drug exposure (www.accessdata.fda. gov/drugsatfda_docs/nda/2004/21-144_Ketek_BioPharmr_P1.pdf; study 1067). Based on clarithromycin parameters $\left(\mathrm{F}_{\mathrm{a}} \mathrm{F}_{\mathrm{g}}=0.89, \mathrm{k}_{\mathrm{a}}=\right.$ $0.0113 \min _{-1}, \mathrm{f}_{\mathrm{u}}=0.30, \mathrm{CYP} 3 \mathrm{~A} 4 \mathrm{~K}_{\mathrm{i}}=57.5 \mu \mathrm{M}, \mathrm{K}_{\mathrm{I}}=13.2 \mu \mathrm{M}, \mathrm{k}_{\text {inact }}=$ $0.058 \mathrm{~min}_{-1}$, OATP1B1 $\mathrm{K}_{\mathrm{i}}=5.3 \mu \mathrm{M}$ and $\left.C_{\operatorname{max~ss}}=3.83 \mu \mathrm{M}\right)$ (Chu et al., 1992; Obach et al., 2006; Zimmerlin et al., 2011; Yoshida et al., 2012; Ikawa et al., 2014; Vermeer et al., 2016; www.accessdata.fda.gov/ drugsatfda_docs/nda/2004/21-144_Ketek_BioPharmr_P1.pdf) yielding calculated $\left[\mathrm{I}_{\mathrm{g}}\right]$ and $\left[\mathrm{I}_{\mathrm{in}} \max \mathrm{u}\right]$ values of 22.4 and $2.493 \mu \mathrm{M}$, predicted AUCRs

TABLE 4

Predicted vs. observed AUC increases of simvastatin acid after coadministration or dose staggering (12 h apart) with telithromycin based upon combined reversible inhibition/inactivation of intestinal CYP3A4 $\left(f_{\mathrm{m}}=0.4\right)$ and hepatic CYP3A4 $\left(f_{\mathrm{m}}=0.83\right)$ with inhibition of hepatic OATP1B1 $\left(f_{\mathrm{e}}=0.79\right)$

Numbers in square brackets are the calculated predicted AUCR range using the upper and lower $95 \%$ confidence intervals determined for each inhibitory kinetic parameter given in Table 1. To

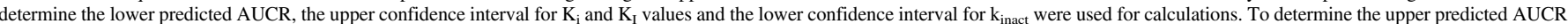
the lower confidence interval for $\mathrm{K}_{\mathrm{i}}$ and $\mathrm{K}_{\mathrm{I}}$ values, and the upper confidence interval for $\mathrm{k}_{\text {inact }}$ were used for calculations.

\begin{tabular}{|c|c|c|c|c|c|c|c|}
\hline \multirow[b]{2}{*}{ Perpetrator Drug } & \multirow{2}{*}{$\begin{array}{l}\text { Dose } \\
(\mathrm{mg})\end{array}$} & \multicolumn{3}{|c|}{ Predicted Fold Increase in AUC due to Inhibition of Composite Pathways } & \multirow{2}{*}{$\begin{array}{c}\text { Overall } \\
\text { Predicted AUCR }\end{array}$} & \multirow{2}{*}{$\begin{array}{c}\text { Clinically } \\
\text { Observed } \\
\text { AUCR }\end{array}$} & \multirow{2}{*}{$\begin{array}{c}\text { Primary } \\
\text { Mechanism of DDI }\end{array}$} \\
\hline & & $\begin{array}{c}\text { Intestinal CYP3A4 } \\
\text { (theoretical maximum = 1.67) }\end{array}$ & $\begin{array}{c}\text { OATP1B1 } \\
\text { (theoretical maximum }=4.76 \text { ) }\end{array}$ & $\begin{array}{c}\text { Hepatic CYP3A4 } \\
\text { (theoretical maximum }=5.88 \text { ) }\end{array}$ & & & \\
\hline & $\mathrm{mg}$ & & & & & & \\
\hline $\begin{array}{l}\text { Telithromycin } \\
\quad \text { (coadministered) }\end{array}$ & 800 & $1.66[1.66-1.67]$ & $1.16[1.12-1.22]$ & $5.62[5.45-5.74]$ & $10.8[10.1-11.7]$ & $9.4^{a}-10.8^{b}$ & $\begin{array}{l}\text { CYP3A4 reversible } \\
\text { inhibition/inactivation }\end{array}$ \\
\hline $\begin{array}{l}\text { Telithromycin } \\
(12 \mathrm{~h} \text { apart })\end{array}$ & 800 & $1.49[1.38-1.58]^{c}$ & $1.01[1.00-1.01]^{c}$ & $3.60[2.79-4.62]^{c}$ & $5.4[3.85-7.37]$ & $4.3^{a}$ & CYP3A4 inactivation \\
\hline
\end{tabular}

${ }^{a}$ Study Number 1065; Drug FDA approval package review 1 (Clinical Pharmacology Biopharmaceutics Review Part 1, accessed via Drugs@FDA database; www.accessdata.fda.gov/ drugsatfda_docs/nda/2004/21-144_Ketek_BioPharmr_P1.pdf).

${ }^{b}$ Study Number 1048; Drug FDA approval package review 4 (Clinical Pharmacology Biopharmaceutics Review Part 4, accessed via Drugs@FDA database; www.accessdata.fda.gov/ drugsatfda_docs/nda/2004/21-144_Ketek_BioPharmr_P4.pdf).

${ }^{c}$ Using $\left[\mathrm{C}_{12 \mathrm{~h}} \mathrm{u}\right]$ plasma concentration for [I]. 
due to the inhibition of intestinal CYP3A4, OATP1B1, and hepatic CYP3A4 were $1.66,1.34$, and 5.08, respectively. The resulting predicted combined AUCR of 11.3 was similar to the clinically observed value. Interestingly, like telithromycin, the magnitude of DDI due to clarithromycin is primarily a consequence of the time-dependent inhibition of CYP3A4. Correct predictions of simvastatin acid AUCR for DDIs mediated by telithromycin and clarithromycin validate the modified, integrated mechanistic static equation in the model. Moreover, the finding for the DDIs above that the predicted AUCR values calculated by the net-effect model (Fahmi et al., 2009; detailed in http://www.fda.gov/downloads/Drugs/GuidanceComplianceRegulatoryInformation/Guidances/UCM581965.pdf) were identical to those values derived via eq. 3 verified the model (data not shown).

In conclusion, the modified mechanistic static eq. 3 incorporating both reversible and time-dependent inhibition for P450 enzymes, which has been successfully applied in this study to understand the mechanism of DDI between simvastatin acid and telithromycin, will provide a useful tool for use in drug discovery and development toward quantitative prediction of more complex DDIs, which can subsequently inform decision-making and clinical protocol design for patient studies.

\section{Acknowledgments}

We thank Chris Turner, Andrew Blainey, and Roisin Toohey for conducting some of the in vitro enzyme experiments.

\section{Authorship Contributions}

Participated in research design: Elsby and Plant.

Conducted experiments: Hare, Neal, Outteridge, Pearson, and Gill.

Performed data analysis: Elsby, Hare, Neal, Outteridge, Pearson, and Gill.

Wrote or contributed to the writing of the manuscript: Elsby, Hare, Neal, Outteridge, Pearson, Plant, Gill, Butler, and Riley.

\section{References}

Cheng Y and Prusoff WH (1973) Relationship between the inhibition constant (K1) and the concentration of inhibitor which causes 50 per cent inhibition (I50) of an enzymatic reaction. Biochem Pharmacol 22:3099-3108.

Chu SY, Deaton R, and Cavanaugh J (1992) Absolute bioavailability of clarithromycin after oral administration in humans. Antimicrob Agents Chemother 36:1147-1150.

Egan A and Colman E (2011) Weighing the benefits of high-dose simvastatin against the risk of myopathy. $N$ Engl J Med 365:285-287.

Elsby R, Hilgendorf C, and Fenner K (2012) Understanding the critical disposition pathways of statins to assess drug-drug interaction risk during drug development: it's not just about OATP1B1. Clin Pharmacol Ther 92:584-598.
Elsby R, Martin P, Surry D, Sharma P, and Fenner K (2016) Solitary inhibition of the breast cancer resistance protein efflux transporter results in a clinically significant drug-drug interaction with rosuvastatin by causing up to a 2 -fold increase in statin exposure. Drug Metab Dispos 44 398-408.

Fahmi OA, Hurst S, Plowchalk D, Cook J, Guo F, Youdim K, Dickins M, Phipps A, Darekar A, Hyland R, et al. (2009) Comparison of different algorithms for predicting clinical drug-drug interactions, based on the use of CYP3A4 in vitro data: predictions of compounds as precipitants of interaction. Drug Metab Dispos 37:1658-1666.

Gibbs MA, Thummel KE, Shen DD, and Kunze KL (1999) Inhibition of cytochrome P-450 3A (CYP3A) in human intestinal and liver microsomes: comparison of $\mathrm{K}_{\mathrm{i}}$ values and impact of CYP3A5 expression. Drug Metab Dispos 27:180-187.

He K, Woolf TF, and Hollenberg PF (1999) Mechanism-based inactivation of cytochrome P-450 3A4 by mifepristone (RU486). J Pharmacol Exp Ther 288:791-797.

Ikawa K, Kikuchi E, Kikuchi J, Nishimura M, Derendorf H, and Morikawa N (2014) Pharmacokinetic modelling of serum and bronchial concentrations for clarithromycin and telithromycin, and site-specific pharmacodynamic simulation for their dosages. J Clin Pharm Ther 39:411-417.

Izumi S, Nozaki Y, Maeda K, Komori T, Takenaka O, Kusuhara H, and Sugiyama Y (2015) Investigation of the impact of substrate selection on in vitro organic anion transporting polypeptide 1B1 inhibition profiles for the prediction of drug-drug interactions. Drug Metab Dispos 43:235-247.

Lee JH and Lee MG (2007) Dose-dependent pharmacokinetics of telithromycin after intravenous and oral administration to rats: contribution of intestinal first-pass effect to low bioavailability. J Pharm Pharm Sci 10:37-50.

Obach RS, Walsky RL, and Venkatakrishnan K (2007) Mechanism-based inactivation of human cytochrome p450 enzymes and the prediction of drug-drug interactions. Drug Metab Dispos 35: 246-255.

Obach RS, Walsky RL, Venkatakrishnan K, Gaman EA, Houston JB, and Tremaine LM (2006) The utility of in vitro cytochrome $\mathrm{P} 450$ inhibition data in the prediction of drug-drug interactions. I Pharmacol Exp Ther 316:336-348.

Seithel A, Eberl S, Singer K, Auge D, Heinkele G, Wolf NB, Dörje F, Fromm MF, and König J (2007) The influence of macrolide antibiotics on the uptake of organic anions and drugs mediated by OATP1B1 and OATP1B3. Drug Metab Dispos 35:779-786.

Sharma P, Butters CJ, Smith V, Elsby R, and Surry D (2012) Prediction of the in vivo OATP1B1mediated drug-drug interaction potential of an investigational drug against a range of statins. Eur J Pharm Sci 47:244-255.

Vermeer LM, Isringhausen CD, Ogilvie BW, and Buckley DB (2016) Evaluation of ketoconazole and its alternative clinical CYP3A4/5 inhibitors as inhibitors of drug transporters: the in vitro effects of ketoconazole, ritonavir, clarithromycin, and itraconazole on 13 clinically-relevant drug transporters. Drug Metab Dispos 44:453-459.

Vieira ML, Zhao P, Berglund EG, Reynolds KS, Zhang L, Lesko LJ, and Huang SM (2012) Predicting drug interaction potential with a physiologically based pharmacokinetic model: a case study of telithromycin, a time-dependent CYP3A inhibitor. Clin Pharmacol Ther 91 $700-708$.

Williamson B and Riley RJ (2017) Hepatic transporter drug-drug interactions: an evaluation of approaches and methodologies. Expert Opin Drug Metab Toxicol 13:1237-1250.

Yoshida K, Maeda K, and Sugiyama Y (2012) Transporter-mediated drug--drug interactions involving OATP substrates: predictions based on in vitro inhibition studies. Clin Pharmacol Ther 91:1053-1064.

Zimmerlin A, Trunzer M, and Faller B (2011) CYP3A time-dependent inhibition risk assessmen validated with 400 reference drugs. Drug Metab Dispos 39:1039-1046.

Address correspondence to: Dr. Robert Elsby, Cyprotex Discovery Limited, No 24 Mereside, Alderley Park, Cheshire SK10 4TG, UK. E-mail: r.elsby@cyprotex.com 